\title{
An assessment of the frequency of blood transfusion before and after starting hydroxyurea therapy in children of sickle cell anemia
}

\author{
Shikha Gupta ${ }^{1}$, Prachi Chaudhary $^{2}$, Amrita Chauhan $^{3}$, Preeti Malpani ${ }^{4}$ \\ ${ }^{1}$ Post Graduate Resident, ${ }^{2}$ Associate Professor, ${ }^{3}$ Senior Resident, ${ }^{4}$ Professor, Department of Paediatrics, Mahatma \\ Gandhi Memorial Medical College, Indore, Madhya Pradesh, India
}

Background: Hydroxyurea therapy is a known effective and safe therapy for the treatment of sickle cell anemia (SCA). Although it is used worldwide in our Madhya Pradesh based setup, it is underutilized due to economic reasons and unaware practitioners about its use. Aims and Objectives: The Objective of the study is to assess the frequency of blood transfusion year before and after starting hydroxyurea therapy in children of SCA. Materials and Methods: An ambispective observational study was performed at MGM Medical College Indore over a period of 1 year 8 months. One hundred and ninety patients were enrolled after taking a complete history, then started on Hydroxyurea and followed up every 2 months till 1 year. On follow-up, frequency of blood transfusion was noted along with routine investigations and for any side effects. Results: Of 190 total recruited patients, 84 were studied at the end because of loss to follow-up due to various reasons. Significant decrease in the need for blood transfusion was observed within 1 year of starting Hydroxyurea $(P<0.05)$. Conclusion: The use of hydroxyurea in our native population at our setup can decrease the need for frequent blood transfusion in sickle cell patients.

Key words: Sickle cell anemia and hydroxyurea; Hydroxyurea and blood transfusion; Blood transfusion in sickle cell anemia; Drugs for sickle cell anemia.

\section{Access this article online}

Website:

http://nepjol.info/index.php/AJMS DOI: 10.3126/ajms.v13i2.41506

E-ISSN: 2091-0576

P-ISSN: 2467-9100

Copyright (c) 2022 Asian Journal of Medical Sciences

This work is licensed under a Creative Commons Attribution-NonCommercial 4.0 International License.

\section{INTRODUCTION}

Sickle cell anemia (SCA) is a type of hemoglobinopathy which is a group of blood disorders affecting the structure, function, or production of hemoglobin $(\mathrm{Hb})$. These conditions are usually autosomal recessive inherited and may range from asymptomatic laboratory abnormalities to death in utero. Sickle cell disease (SCD) is caused by a mutation in beta-globin gene that changes the sixth amino acid to valine resulting in HbS. Inheritance of HbS from one parent and another hemoglobinopathy from another parent results various sickle cell syndromes (for e.g., beta-thalassemia). In India, SCD is a common hemoglobinopathy, next to thalassemia.
This variant $\mathrm{Hb}$ polymerizes abnormally rendering red blood corpuscles easily deformable, sticky, and shape like a sickle which abnormally adheres to the endothelium of small venules. These abnormal red blood cells (RBCs) promote unpredictable episodes of microvascular vasoocclusion and premature RBC destruction (hemolytic anaemia). Prominent manifestations include episodes of ischemic pain and ischemic or frank infarction within the spleen, central nervous system, bones, liver, kidneys, and lungs. ${ }^{1}$

The prevalence of carrier state of sickle cell varies from $1 \%$ to $40 \%$ among different tribal groups. Madhya Pradesh has the maximum load with an estimated number of 67,861 
sickle homozygote and 9, 61,492 sickle heterozygote. Out of 45 districts in Madhya Pradesh, 27 districts fall into sickle cell belt.

The prevalence of sickle cell varies from $10 \%$ to $33 \%$ in Madhya Pradesh. It has also been estimated that 13,432 pregnancies would be at risk of getting a toddler with SCD in Madhya Pradesh and thus the expected annual births of sickle homozygote would be $3358 .^{2}$

Although the SCD is present from birth, symptoms are rare before the age of the 3-6 months with an increased incidence of adverse events coincident with the physiologic fall in fetal $\mathrm{Hb}(\mathrm{HbF}){ }^{3}$ SCA was first described in south Indian tribal groups and subsequently in central India. ${ }^{4}$ Vaso-occlusive pain episodes are one of the most common clinical features associated with SCA. ${ }^{5}$

Bone marrow transplantation is only cure for SCD, which usually necessitates a human lymphocyte antigen-identical family member donor. There is $85 \%$ disease-free survival rate, 3 with a $7 \%$ transplant-related mortality rate and a $9 \%$ graft failure rate. Barriers to the widespread use of bone marrow transplantation in patients with SCD include a scarcity of suitable bone marrow donors and therefore the got to identify patients with an adequate risk-to-benefit ratio.

For these reasons, drug therapy for SCD continues to be the first and primary mode of disease management that specialize in decreasing the complications of this disease. ${ }^{6}$

Hydroxyurea, a myelosuppressive agent, is that the only effective drug proven to decrease the frequency of painful episodes. It raises the extent of $\mathrm{HbF}$ and thus the $\mathrm{Hb}$ level. It was first tested in SCD in 1984. It generally reduces the rate of painful crisis by $50 \%$. It also reduces the rate of blood transfusions and acute chest syndrome episodes by $\sim 50 \%$ in adults. It was developed as an anticancer drug and is also been used to treat myeloproliferative disordersleukemia, melanoma, and ovarian cancer.

Side effects; includes anorexia, nausea, vomiting, low absolute neutrophil count (ANC), bone marrow suppression, elevation of liver enzymes, and infertility. ${ }^{7}$

The phase 3 NHLBI - sponsored multicentre study of hydroxyurea trial proved clinical efficacy for preventing acute vaso-occlusive crisis in severely affected adults. Based on this cumulative evidence, hydroxyurea has emerged as a valuable therapeutic option for children and adolescents with frequent vaso occlusive events; recent evidence documents sustained long-term benefits with prevention or reversal of chronic organ damage. ${ }^{8}$
Although questions remain regarding its long-term risks and benefits, the current study is conducted to analyze clinico-hematological response in patients of SCD receiving hydroxyurea.

\section{Rationale}

Hydroxyurea therapy is a known effective and safe therapy for treatment of SCA, although it is used worldwide in our MP based setup it is underutilized because of high cost, unawareness, and unrealistic fear among health care workers regarding its use in SCD, along with this inconsistent medical delivery system also contribute to less frequent use of Hydroxyurea in our setup.

\section{Aims and objectives}

To study the frequency of blood transfusion year before and after starting hydroxyurea therapy in children of SCA.

\section{MATERIALS AND METHODS}

The present study was carried out at MGM medical college Indore from January 2019 to August 2020. After taking written informed consent from the parents, the patients with SCD were included in the study population.

\section{Source of data}

All patients attending Dept. of Paediatrics, M.Y Hospital, Indore and Chacha Nehru Bal Chikitsalaya Evam Anusandhan Kendra, Indore.

The study sample was based on the prevalence of SCD, in Madhya Pradesh. Minimal sample size was required in the study was 100 .

\section{Study design}

Retrospective and prospective (ambispective) observational study.

\section{Inclusion criteria}

- Diagnosed cases of SCD by Hb electrophoresis.

\section{Exclusion criteria}

- Patients $<2$ years of age

- HIV reactive patients

- Patients already on hydroxyurea therapy before enrolment were excluded.

A detailed history, clinical examination, and specific baseline investigations (Complete blood count [CBC], liver function test [LFT], renal function test [RFT], HIV, $\mathrm{Hb}$ electrophoresis), were done before starting Hydroxyurea therapy detailed history questionnaire and Medical records used to know age, sex, caste, age of diagnosis, and frequency of blood transfusion/year. 
The typical starting dose of hydroxyurea was $15-20 \mathrm{mg} / \mathrm{kg} /$ day and doses were adjusted according to ANC (target to be to maintained between 2000 and 2500). Then patients were called for follow-up every 2 months till 1 year.

On follow-up, frequency of blood transfusion was noted. On follow-up specific investigations including CBC, RFT, and LFT done. On each follow up if any, side effects were investigated.

If neutropenia $<1500 / \mathrm{ul}$ and thrombocytopenia $<80,000$ occurs, hydroxyurea therapy was withhold and monitor $\mathrm{CBC}$ with white blood count differentially. When blood counts recover, reinstitute hydroxyurea therapy. Data analyzed as pre-treatment and post-treatment of hydroxyurea therapy.

\section{Statistical analysis}

The data were collected from the proforma of the study and then was compiled in the Microsoft Excel software for the master chart. Statistical Package for the Social Sciences (SPSS) version 22 (IBM SPSS Statistics, Somers NY, USA) was used to analyze data. Chi-square test, Wilcoxon Signed Rank test, Friedman test, and unpaired t-test was used to calculated P-value.

\section{RESULTS}

During the study 190 sickle cell patients were recruited for our study.

- Total recruited patients $=190$

- Lost to follow-up $=106$

- Study population at 12 months $=84$ (out of which 57 were SCA and 27 were SCD).

Out of 84 patients, 34 were male and 46 were female.

\section{Interpretation}

This table shows that the majority of sickle cell patient in our study belong to 6-10 year of age (Table 1).

\section{Table 1: Age distribution of study population}

\begin{tabular}{lcc} 
Age & No of patients & Percent \\
\hline $1-5$ year & 10 & 11.9 \\
$6-10$ year & 42 & 50 \\
$11-15$ year & 24 & 28.6 \\
$>15$ year & 8 & 9.5 \\
Total & 84 & 100.0 \\
\hline
\end{tabular}

Interpretation

This table suggests that therapy with hydroxyurea significantly reduces the need for blood transfusion within 1 year follow up $(\mathrm{P}<0.05)$ (Figure 1 and Table 2).

\section{DISCUSSION}

Hydroxyurea is a standard and accepted therapy for SCD but is less frequently used in our region and also there are no studies regarding its efficacy and side effects in our native SCD population.

So in our study, we used Hydroxyurea as a treatment modality for SCA in order to evaluate its efficacy and safety. A study by $\mathrm{Ndefo}^{2}$ also suggests that although bone marrow transplantation can cure SCD, it is an impractical solution for most Third World countries, which have a high disease burden. Even in the U.S., bone marrow transplantation is limited by the availability of donors. Pharmacological therapies are effective at reducing complications of SCD and are safe and easily administered, and they continue to prolong the life expectancy of patients. ${ }^{6}$

In our present study we observed that Hydroxyurea therapy administered for a period of 1 year, it causes significant reduction in the need of blood transfusion in patient of SCD, the decrease in mean value of blood transfusion before and after 12 month Hydroxyurea was from $5.36 \pm 4.59$ to $0.32 \pm 0.75$ with $\mathrm{P}<0.0001$.

In a study by Jain et al., 2013, states that after Hydroxyurea therapy in sickle cell patient for 12 months the need of blood transfusion was reduced by $79.3 \%$.

In a cohort study by Pondugala et al., ${ }^{10}$ in the Hydroxyurea group, mean blood transfusions after 12 months was decreased $(0.30 \pm 0.47$ as opposed to entry mean blood transfusions of $2.90 \pm 2.93[\mathrm{P}<0.001])$. Whereas in the placebo group, there was no difference in mean blood transfusions after 12 months $(1.90 \pm 1.45$ as opposed to entry mean blood transfusions of $2.60 \pm 3.18$ [ $\mathrm{P}=0.283]$ ). This shows that there was statistically significant decrease in number of blood transfusions required, after 12 months' treatment with Hydroxyurea $(\mathrm{P}<0.001)$ with no significant difference in blood transfusions required in the placebo group who were not given Hydroxyurea therapy $(\mathrm{P}=0.283) \cdot{ }^{10}$

\section{Table 2: Frequency of blood transfusion/year before and after hydroxyurea therapy}

\begin{tabular}{lccccccc} 
Variable & $\mathbf{n}$ & Mean & SD & Minimum & Maximum & 95\% confidence Interval & P-value \\
\hline Blood transfusion before hydroxyurea & 84 & 5.36 & 4.59 & 0 & 12 & Lower 4.076 & $<0.001$ \\
Blood transfusion after hydroxyurea & 84 & 0.32 & 0.75 & 0 & 3 & Upper- 6.007 & \\
\hline
\end{tabular}




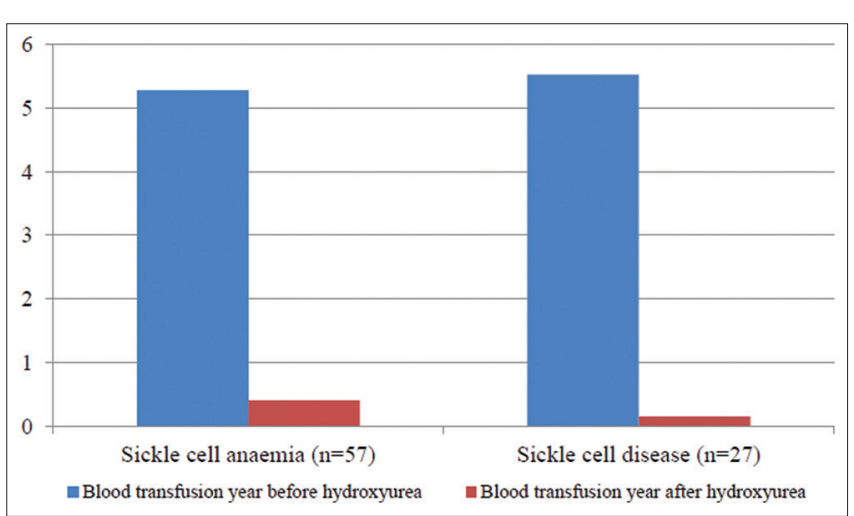

Figure 1: Frequency of blood transfusion a year before and after starting hydroxyurea therapy in sickle cell patients

A study by Agrawal et al.,7 (after Hydroxyurea therapy need for blood transfusion decreases by $50 \%$ ) and Ana Cristina Silva-Pinto I (RBC units transfused decreased from $1.23 \pm 2.25$ to $0.1 \pm 0.3, \mathrm{P}=0.0051$ ), similar outcome was observed and it stated that Hydroxyurea decreases the need for blood transfusion. ${ }^{7,11}$

This decrease in need of RBC units' transfusion in our study may be due to rise in $\mathrm{Hb}$ level associated with Hydroxyurea therapy and decreased hemolysis.

\section{Limitations of the study}

As the patients come to our setup from distant places, loss to follow up was a major setback because of distance as well as economic constraints for travelling.

\section{CONCLUSION}

In our study, we enrolled 121 patients out of which only 84 were able to complete the scheduled follow-up at regular interval of 2 months, i.e., 2, 4, 6, 8, 10, and 12 month. We recorded the baseline value of blood transfusions/year.

We followed the patients at regular interval of 2 months and the above mentioned parameter was compared with the baseline parameter.

It was found that there was a significant reduction in the rate of blood transfusion/year, and thus leading to decreased morbidity with prolonged survival. ${ }^{1}$ So after evaluating the above data, we could conclude that Hydroxyurea is an effective in reducing frequency of blood transfusion in SCA and sickle- $\beta$ Thalassemia disease. Thus based on the above study, we can recommend regular use of hydroxyurea in our native population at our setup in Indore.

\section{ACKNOWLEDGMENT}

A sincere thanks to the Day Care Centre staff nurses and technicians to help us complete the study as well the Department of Pediatrics of our centre.

\section{REFERENCES}

1. Bhatia HM and Rao VR. Genetic Atlas of the Indian Tribes. New Delhi: Institute of Immunohematology, Indian Council of Medical Research; 1986.

2. Colah RB, Mukherjee MB, Martin S and Ghosh K. Sickle cell disease in tribal populations in India. Indian J Med Res. 2015;141(5):509-515.

https://doi.org/10.4103/0971-5916.159492

3. Negi RS. Sickle cell trait in India. A review of known distribution. Bull Anthropol Surv India. 1972;17:439-449.

4. Shrikhande AV, Dani AA, Tijare JR and Agrawal AK. Hematological profile of sickle cell disease in central India. Indian J Hematol Blood Transfus. 2007;23(3):92-98. https://doi.org/10.1007/s12288-008-0005-z

5. Maier-Redelsperger $M$, de Montalembert $M$, Flahault $A$, Neonato MG, Ducrocq R, Masson MP, et al. Fetal hemoglobin and f-cell responses to long- term hydroxyurea treatment in young sickle cell patients. Blood. 1998;91(12):4472-4479.

6. Ndefo UA, MaxwellAE, Nguyen Hand Chiobi TL. Pharmacological management of sickle cell disease. P T. 2008;33(4):238-243.

7. Agrawal RK, Patel RK, Shah V, Nainiwal L and Trivedi B. Hydroxyurea in sickle cell disease: Drug review. Indian J Hematol Blood Transfus. 2014;30(2):91-96.

https://doi.org/10.1007/s12288-013-0261-4

8. Brawley OW, Cornelius LJ, Edwards LR, Gamble VN, Green BL, Inturrisi C, et al. National institutes of health consensus development conference statement: Hydroxyurea treatment for sickle cell disease. Ann Intern Med. 2008;148(12): 932-938.

https://doi.org/10.7326/0003-4819-148-12-200806170-00220

9. Jain DL, Apte M, Colah R, Sarathi V, Desai S, Gokhale A, et al. efficacy of fixed low dose hydroxyurea in indian children with sickle cell anemia: A single centre experience. Indian Pediatr. 2013;50(10):929-933.

https://doi.org/10.1007/s13312-013-0264-0

10. Pondugala SK, Varanasi PK, Rao KM and Vegesna S. To assess the efficacy of hydroxyurea, in children with homozygous sickle cell disease, in the age group of 1 year to 18 years, at tertiary care hospital. J NTR Univ Health Sci. 2012;1(4):227-232.

11. Silva-Pinto AC, Angulo IL, Brunetta DM, Neves FI, Bassi SC, Santis GC, et al. Clinical and hematological effects of hydroxyurea therapy in sickle cell patients: A single-center experience in Brazil. Sao Paulo Med J. 2013;131(4):238-243. https://doi.org/10.1590/1516-3180.2013.1314467 
Authors Contribution:

SG- Concept and design of the study, statistical analysis and interpretation; PC- Interpreted the results; reviewed the literature and manuscript preparation;

PM- Concept, coordination; AC- Prepared the first draft of manuscript, preparation of manuscript and revision of the manuscript.

Work attributed to:

Mahatma Gandhi Memorial Medical College, Indore - 452 001, Madhya Pradesh, India.

Orcid ID:

Dr. Amrita Chauhan- (D) https://orcid.org/0000-0001-5791-3626

Dr Shikha Gupta- (D) https://orcid.org/0000-0002-5126-7536

Dr Prachi Chaudhary- (D) https://orcid.org/0000-0002-4548-4411

Dr Preeti Malpani- https://orcid.org/0000-0002-9039-2970

Source of Support: None, Conflicts of Interest: None. 